\title{
Immobilization of lipase from Mucor miehei and Rhizopus oryzae into mesoporous silica - The effect of varied particle size and morphology
}

Hanna Gustafsson, Emma Johannsson, Albert Barrabino, Magnus Odén and Krister Holmberg

\author{
Linköping University Post Print
}

N.B.: When citing this work, cite the original article.

Original Publication:

Hanna Gustafsson, Emma Johannsson, Albert Barrabino, Magnus Odén and Krister Holmberg, Immobilization of lipase from Mucor miehei and Rhizopus oryzae into mesoporous silica - The effect of varied particle size and morphology, 2012, Colloids and Surfaces B: Biointerfaces, (100), 22-30.

http://dx.doi.org/10.1016/j.colsurfb.2012.04.042

Copyright: Elsevier

http://www.elsevier.com/

Postprint available at: Linköping University Electronic Press

http://urn.kb.se/resolve?urn=urn:nbn:se:liu:diva-78683 
Immobilization of lipase from Mucor miehei and Rhizopus oryzae into mesoporous silica

\section{- The effect of varied particle size and morphology}

Hanna Gustafsson ${ }^{\mathrm{a}}$, Emma M. Johansson ${ }^{\mathrm{b}}$, Albert Barrabino ${ }^{\mathrm{a}}$, Magnus Odén ${ }^{\mathrm{b}}$ and Krister

Holmberg $^{\mathrm{a} *}$

$5{ }^{a}$ Chalmers University of Technology, Department of Chemical and Biological Engineering, SE-412 96 Gothenburg, Sweden.

${ }^{\mathrm{b}}$ Linköping University, Department of Physics, Chemistry and Biology, SE-581 83

Linköping, Sweden

$10 *$ Corresponding author.

E-mail address: krister.holmberg@ chalmers.se

Tel: +46 317722969

Fax: +46317722969 
Immobilization of enzymes usually improves the recyclability and stability and can sometimes also improve the activity compared to enzymes free in solution. Mesoporous silica is a widely studied material as host for immobilized enzymes because of its large internal surface area and tunable pores. It has previously been shown that the pore size is critical both

20 for the loading capacity and for the enzymatic activity; however, less focus has been given to the influence of the particle size. In this work the effect of particle size and particle morphology on the immobilization of lipase from Mucor miehei and Rhizopus oryzae have been investigated. Three kinds of mesoporous silica, all with $9 \mathrm{~nm}$ pores but with varying particle size $(1000 \mathrm{~nm}, 300 \mathrm{~nm}$ and $40 \mathrm{~nm})$ have been synthesized and were used as host for 25 the lipases. The two lipases, which have the same molecular size but widely different isoelectric points, were immobilized into the silica particles at varied $\mathrm{pH}$ values within the interval 5 to 8 . The $300 \mathrm{~nm}$ particles were proven to be the most suitable carrier with respect to specific activity for both enzymes. The lipase from Mucor miehei was more than four times as active when immobilized at $\mathrm{pH} 8$ compared to free in solution whereas the difference was

30 less pronounced for the Rhizopus oryzae lipase.

Keywords: Mesoporous silica, immobilization, enzymes, lipase, biocatalysis, particle morphology

Abbreviations:

MPS mesoporous silica

35 SBA-15 Santa Barbara Amorphous type material

HMM Hiroshima Mesoporous Materials

TEOS tetraethylorthosilicate

CTAB cetyltrimethylammonium bromide

AIBA 2,2'-azodiisobutyramidine dihydrochloride

40 pNPA 4-nitrophenyl acetate

DMSO dimethyl sulfoxide 


\section{Introduction}

Ordered mesoporous materials can be used as host for enzymes [1-3], as well as for synthetic homogeneous catalysts [4,5]. No covalent immobilization is needed provided the pores have suitable diameter; the soluble catalyst resides in the pores and meets the substrate at the pore openings. Particles loaded with an enzyme or a homogeneous catalyst in the waterfilled pores are either dispersed in an aqueous [1-4] or a non-aqueous [6,7] solution in which the reactants are dissolved. The reverse has also been described: particles with hydrophobized pores housing a hydrophobic homogeneous catalyst dissolved in an apolar medium and with water as the surrounding phase [5]. The approach of having the soluble catalyst entrapped in the pores of a mesoporous material is attractive from several points of view. The systems are robust and the work-up procedure is extremely facile; the catalyst-loaded particles are simply removed from the reaction mixture by filtration or centrifugation. It has been shown both for an enzyme [6] and for a synthetic homogeneous catalyst [5] that the loaded particles can be reused several cycles.

Ordered mesoporous materials are materials with pores typically in the size range of 2 to $15 \mathrm{~nm}$ with either hexagonal or cubic geometry. Most mesoporous materials used as host for soluble catalysts are silicates but other mesoporous oxides, such as alumina and titania have also been employed for the purpose [6]. The materials are made by a templating procedure, using an organic template that is subsequently removed by solvent extraction or by calcination or by a combination of these. The pore dimension can be tailored with high precision by the choice of templating molecule and by the synthesis conditions [8]. The ability to tailor-make the mesoporous material with respect to pore size is attractive when the pores are used as hosts for catalysts and we [9] and others [10-12] have studied and determined the optimum size to house a specific enzyme. In a recent publication we have shown that for Mucor miehei lipase with a molecular weight of $32000 \mathrm{Da}$ and a 
hydrodynamic diameter of $4.5 \mathrm{~nm}$, pores with a diameter of $9 \mathrm{~nm}$ were optimal while for trypsin that has a molecular weight of $23000 \mathrm{Da}$ and a hydrodynamic diameter of $3.8 \mathrm{~nm}, 6$ nm pores were optimal [9].

While several papers deal with the issue of pore dimension to achieve best results with an enzyme entrapped in a mesoporous material, there exists to the best of our knowledge no systematic study of the role of particle size on the efficiency of a biocatalytic process with the enzyme entrapped in the pores of particles of a mesoporous material. One may anticipate that smaller particles would be beneficial because the larger surface to volume ratio should mean increased exposure of pore opening toward the surrounding phase but this seems not to have been properly investigated.

We here report synthesis and characterization of mesoporous silica particles with dimensions of 1000, 300 and $40 \mathrm{~nm}$, all having pores with a diameter of $9 \mathrm{~nm}$. The materials were used as hosts for two enzymes: the same Mucor miehei lipase that was used in the previous study and a lipase from Rhizopus oryzae. The two lipases were chosen because they have the same molecular weight, $32000 \mathrm{Da}$, but they differ widely in isoelectric point (pI). The Mucor miehei lipase has a pI of 3.8 while the pI of the lipase from Rhizopus oryzae is 7.6. The use of enzymes of same size but different net charge opens possibilities to assess the importance of the interactions between the enzyme and the pore walls. In order to shed light on such interactions loading of the enzymes were performed at different $\mathrm{pH}$ values within the interval 5 to 8 .

The pore dimension, $9 \mathrm{~nm}$, was chosen since, as mentioned above, we have previously found that size to be optimal for the Mucor miehei lipase. Thus, in this work no further optimization of the pore diameter was made. 


\subsection{Chemicals}

Pluronic P123 $\left(\mathrm{EO}_{20} \mathrm{PO}_{70} \mathrm{EO}_{20}, \mathrm{Mw}=5800\right)$, cetyltrimethylammonium bromide $(\mathrm{CTAB}$, $\geq 99 \%$ ), tetraethylorthosilicate (TEOS, $\geq 99 \%$ ), $\alpha, \alpha^{\prime}$-azodiisobutyramidine dihydrochloride (AIBA, 97\%), L-lysine ( $\geq 98 \%$ ), hydrochloric acid (37 wt \%), 4-nitrophenyl acetate (pNPA)

95 and dimethyl sulfoxide (DMSO, $\geq 99.9 \%$ ) were all purchased from Sigma.

\subsection{Enzymes}

The two enzymes investigated, lipase from Mucor miehei (MML, $\geq 4000$ units/mg solid (using olive oil)) and lipase from Rhizopus oryzae (ROL, $\geq 30$ units/mg solid (using olive oil)) were purchased from Sigma and used without further purification. These two lipases are

100 similar in size and structure but they differ in isoelectric point (pI). MML has a pI of 3.8 and the $\mathrm{pI}$ of ROL is 7.6 .

\subsection{Preparation of the mesoporous silica materials}

In this study, mesoporous silica materials with three different particle morphologies were used as hosts for the enzymes. Two of the materials are called SBA-15 and were synthesized using protocols adapted from Zhao et al. [13,14] and Johansson et al. [15], where Pluronic P123 is used as structure directing agent and TEOS as the silica source. In the first synthesis $4.0 \mathrm{~g}$ of $\mathrm{P} 123$ and $8 \mathrm{~g}$ of $\mathrm{K}_{2} \mathrm{PO}_{4}$ were dissolved in $120 \mathrm{~g}$ of $2 \mathrm{M} \mathrm{HCl}$ and $30 \mathrm{~g}$ of deionized water. The mixture was vigorously stirred at $35{ }^{\circ} \mathrm{C}$ until the polymer was dissolved. $8.5 \mathrm{~g}$ of TEOS was added and the solution was stirred at $35{ }^{\circ} \mathrm{C}$ for an additional 8 minutes and then

110 kept under static conditions for $24 \mathrm{~h}$. The gel mixture was transferred to a stainless steel pressure autoclave with Teflon container and was aged for $24 \mathrm{~h}$ at $140{ }^{\circ} \mathrm{C}$. The solid precipitate was recovered by vacuum filtration, washed with deionized water and dried. 
Finally, the template was removed from the product through calcination in air, going from room temperature to $550{ }^{\circ} \mathrm{C}$ during $8 \mathrm{~h}$ followed by heating at $550{ }^{\circ} \mathrm{C}$ for another $6 \mathrm{~h}$. $\mathrm{M} \mathrm{HCl}$ solution. The mixture was stirred at $20{ }^{\circ} \mathrm{C}$ until the polymer was dissolved. $1 \mathrm{ml}$ heptane was premixed with $5.5 \mathrm{ml}$ TEOS and then added to the micellar solution. The reaction mixture was kept under vigorous stirring for 4 min and then under static conditions for $1 \mathrm{~h}$. After the reaction the solution was transferred to a Teflon flask for hydrothermal treatment at $100{ }^{\circ} \mathrm{C}$ for $24 \mathrm{~h}$. The product was filtered and washed with distilled water. Finally, the product was calcined at $550{ }^{\circ} \mathrm{C}$ for $5 \mathrm{~h}$ with a ramp of $5{ }^{\circ} \mathrm{C} / \mathrm{min}$.

The third material is called Hiroshima Mesoporous Materials (HMM) and was synthesized using a protocol adapted from Nandiyanto et al. [16], where CTAB is used as the structure directing agent, TEOS as silica source, octane and styrene as hydrophobic components and lysine as a catalyst and as an agent to control particle growth. An oil-in-water emulsion was formed with styrene, octane and TEOS constituting the oil phase. Hydrolysis and condensation of TEOS into silica and polymerization of styrene into polystyrene were taking place simultaneously inside the drops. In the synthesis $4.0 \mathrm{~g}$ of CTAB was mixed with $124 \mathrm{~g}$ deionized water, $39.7 \mathrm{~g}$ n-octane and $90 \mathrm{mg} \mathrm{L}$-lysine and the mixture was vigorously stirred for $1 \mathrm{~h}$ at $70{ }^{\circ} \mathrm{C} .5 .54 \mathrm{~g}$ styrene monomer, $4.0 \mathrm{~g}$ TEOS and $155 \mathrm{mg}$ AIBA were added to the system and the mixture was stirred and kept under a $\mathrm{N}_{2}$ atmosphere at $70{ }^{\circ} \mathrm{C}$ for $20 \mathrm{~h}$. Prior to use the styrene monomer had been prewashed with $2.5 \mathrm{M} \mathrm{NaOH}$ to remove the stabilizer. Then the suspension was decanted into a funnel and cooled to room temperature overnight. Finally, the octane was evaporated and the precipitate recovered through 135 calcination, going from room temperature to $550{ }^{\circ} \mathrm{C}$ during $8 \mathrm{~h}$ followed by heating at $550{ }^{\circ} \mathrm{C}$ for $6 \mathrm{~h}$. 


\subsection{Characterization}

Transmission electron microscopy (TEM; JEOL JEM-1200 EX II TEM), operated at 120 $\mathrm{kV}$, was used to determine the pore structure and also the particle size of HMM. The samples

140 were grinded, dispersed in ethanol, put in an ultrasonic bath and then dropped onto a holey carbon-coated copper grid. The ethanol was subsequently evaporated.

The morphology of the MPS particles was characterized by scanning electron microscopy (SEM; Leo Ultra 55 FEG SEM).

Small angle X-ray scattering (SAXS) experiment on MPS-40 was performed at the

145 MAX-lab I911-4 beamline in Lund, Sweden. The beam $(1.2 \AA \times 1.2 \AA)$ with a radiation wavelength of $0.91 \AA$ was focused on the detector. The data were collected with a twodimensional Mar165 CCD detector. The distance between sample and collector was $2.0 \mathrm{~m}$ and the q-range was $0.01-0.3 \AA^{-1}$. The measurement time was $360 \mathrm{~s}$. The SAXS measurement on MPS-300 was performed on a PANalytical Empyrean with a radiation wavelength of 1.54

$150 \AA$ A.

Nitrogen sorption isotherms were measured using a Micromeritics ASAP 2010 instrument. Prior to the measurements the calcined MPS samples were degassed in vacuum at $225{ }^{\circ} \mathrm{C}$ for $2 \mathrm{~h}$. The pore size distributions were determined using the BJH (Barrett-JoynerHalenda) method based on the adsorption isotherms [17] and the surface area was determined using the BET (Brunauer-Emmett-Teller) procedure [18].

Surface tension measurements of the lipase solutions were performed using an optical tensiometer, Attension, Theta Lite, KSV Instruments in pendant drop shape analysis.

\subsection{Enzyme immobilization}

$18.75 \mathrm{mg}$ of mesoporous silica were dispersed in $500 \mu 1100 \mathrm{mM}$ potassium phosphate 160 buffer at $\mathrm{pH} 6$ and sonicated for 10 minutes to prevent particle agglomeration. $250 \mu 1$ of 
MML or ROL solution (2 $\mathrm{mg} / \mathrm{ml})$, dissolved in the same buffer, were added to the dispersion and the mixture was shaken for 24 hours at $25{ }^{\circ} \mathrm{C}$ using a thermomixer. The particles were washed three times with $500 \mu \mathrm{l}$ phosphate buffer and separated from the buffer by centrifugation. The amount of immobilized lipase was estimated by measuring the residual

165 protein concentration in the supernatant with UV adsorption at $280 \mathrm{~nm}$ using an Agilant HP8453 spectrophotometer.

The silica material giving rise to the most active lipase was used further to study $\mathrm{pH}$ dependence of MML and ROL during immobilization, using phosphate buffers at $\mathrm{pH} 5,6,7$ and 8 .

\subsection{Lipase activity assay}

The activity of immobilized lipase was estimated by monitoring the catalytic hydrolysis of 4-nitrophenyl acetate (pNPA) into 4-nitrophenol (pNP, $\varepsilon_{\text {molar }}=14200 \mathrm{M}^{-1} \mathrm{~cm}^{-1}$ ). Lipaseloaded mesoporous silica was resuspended in $1 \mathrm{ml}$ phosphate buffer $(50 \mathrm{mM}, \mathrm{pH}$ 7). The particles were separated from the buffer through centrifugation $(5 \mathrm{~min}, 16000 \mathrm{G})$, the

175 supernatant was removed and new buffer was added. This procedure was repeated in order to remove any released enzyme. Due to poor solubility in water pNPA was dissolved in DMSO and then dropwise added to the buffer. The dispersed and washed sample was added to the substrate solution and incubated at $37{ }^{\circ} \mathrm{C}$ for $1 \mathrm{~h}$. The amount of pNP was determined spectrophotometrically at $400 \mathrm{~nm}$. The specific activity was defined as product yield/mass of enzyme ( $\mu \mathrm{M} \mathrm{pNP} / \mu \mathrm{g}$ lipase). The stability of the lipase loaded materials was studied by measuring the activity of the samples over time. The same assay was used for lipase free in solution. No catalytic activity was observed for mesoporous silica without encapsulated lipase. 


\subsection{Leakage}

Throughout the activity measurements the amount of lipase that had leached out of the porous particles was analysed by collecting the supernatants from the washing step and measuring the residual protein concentration with UV spectroscopy at $280 \mathrm{~nm}$.

\section{Results and discussion}

\subsection{Characterization of mesoporous silica}

Three types of mesoporous silica materials with varying particle size and morphology but with similar pore size were synthesized and used as support for two different lipases. The morphological and structural characterization of the mesoporous silica particles was performed by the combined use of SEM, TEM, nitrogen physisorption and SAXS. The obtained materials are referred to as MPS-X, where $\mathrm{X}$ is the particle size in nanometer.

In the first synthesis an inorganic salt $\left(\mathrm{K}_{2} \mathrm{PO}_{4}\right)$ was added to the SBA-15 protocol. The conventional synthesis of SBA-15 yields rod-shaped particles, condensed into clusters [9]. The addition of the potassium salt together with the use of static conditions during the condensation resulted in particles with a different type of morphology. The particles were broader and shorter and were also less aggregated compared to the regular rod-shaped particles (Fig. 1a). It has previously been shown that some inorganic salts of polyvalent anions can enhance the interaction between silica species and the polyoxyethylene segments of the nonionic block copolymer, thereby affecting the morphology of the silica particles $[19,20]$. It has also been demonstrated that particle agglomeration can be avoided by decreasing the stirring time during the silica condensation step [21]. The size of the particles obtained by the modified SBA-15 synthesis was around $1000 \mathrm{~nm}$ (MPS-1000).

In the second synthesis, which is also a modified SBA-15 procedure, smaller particles, about $300 \mathrm{~nm}$ (MPS-300) with a rod-shaped morphology, were obtained by decreasing the 
stirring time in a low temperature synthesis $\left(20{ }^{\circ} \mathrm{C}\right)$ with added heptane and $\mathrm{NH}_{4} \mathrm{~F}$. It has previously been shown that a low temperature during the synthesis in combination with additions of heptane and $\mathrm{NH}_{4} \mathrm{~F}$ yields particles with short and wide pores, $12-18 \mathrm{~nm}$ in diameter, depending on the heptane concentration. The particles attach to each other to form fibers or sheets depending on the synthesis conditions [22]. By decreasing the stirring time and increasing the $\mathrm{HCl}$ concentration, the particle agglomeration can be avoided by passivation of the hydroxyl groups on the particle surfaces and by reducing the hydrolysis and condensation rates of TEOS [20]. Here, the amount of heptane in the reaction mixture was decreased compared to previous works in order to decrease the pore diameter to $9 \mathrm{~nm}$, This yielded even shorter particles compared to previous studies. The particles are shown in Fig. $1 b$.

The smallest particles (MPS-40) were obtained by an entirely different procedure compared to the SBA-15 synthesis [16]. An emulsion was formed with styrene, octane and the silica source, TEOS, constituting the oil phase. A cationic surfactant, CTAB, was used as emulsifier. Silica condensation and styrene polymerization were initiated simultaneously inside the oil drops, resulting in a composite material with isolated domains of silica and polystyrene. The particles were prevented from growing by the presence of an amino acid, Llysine, which covered the composite particles formed. Spherical mesoporous silica particles around $40 \mathrm{~nm}$ in diameter were obtained after removal of the surfactant and the polystyrene by calcination (Fig. 1c and 1d).

Typical TEM micrographs of calcined MPS-1000 and MPS-300, shown in Fig. 2a and $2 b$, respectively displayed hexagonal patterns with long range order and uniform pores. The TEM micrographs of MPS-40 (Fig. 2c and 2d), showed quite monodisperse particles but with non-ordered pore structure. Instead of cylindrical uniform pores, as for MPS-1000 and MPS- 
300, the pores were slit-shaped and more varied with respect to both size and shape. A particle size around $40 \mathrm{~nm}$ was confirmed.

$\mathrm{N}_{2}$-sorption isotherms of the calcined materials, shown in Fig. 3a, confirm the pore structure observed in the TEM micrographs. MPS-1000 and MPS-300 both exhibit an adsorption-desorption isotherm type IV and HI hysteresis, characteristic for SBA-15 with cylindrical and hexagonally ordered mesopores. MPS-40 also displays a type IV sorption isotherm, representative for a mesoporous material but with $\mathrm{H} 3$ hysteresis, which is characteristic for slit-shaped pores [23]. The pore size distributions (Fig. 3b) for MPS-1000 and MPS-300 are narrow whereas the distribution is very wide for MPS-40. According to the BJH method the obtained pores sizes are around $9 \mathrm{~nm}$ for all three materials (see Table 1).

The SAXS patterns of MPS-300 and MPS-40 are shown in Fig. 4a and 4b, respectively. For MPS-300 three well-resolved peaks are observed that can be indexed (100), (110) and (200), which is characteristic of a two dimensional hexagonal structure. The results are in accordance with previous reports $[13,14]$. As expected, no pore order is observed for MPS-40.

Taken together, the characterization techniques show that the $1000 \mathrm{~nm}$ and the $300 \mathrm{~nm}$ particles have hexagonally ordered uniform pores while the $40 \mathrm{~nm}$ particles have slit-shaped pores without an ordered structure. The $1000 \mathrm{~nm}$ particles have a wide base in relation to the length, the $300 \mathrm{~nm}$ particles are rod-shaped, and the $40 \mathrm{~nm}$ particles are spherical. Important for the use of the particles as hosts for lipases is that they all have pores with a medium diameter of around $9 \mathrm{~nm}$. Values of pore size, surface area, and pore volume of the three materials have been collected in Table 1.

\subsection{Immobilization of MML and ROL in mesoporous silica with varying particle size and morphology}

255 The three synthesized mesoporous silica materials were used as hosts for lipases from Mucor miehei (Mucor miehei lipase; MML) and Rhizopus oryzae (Rhizopus oryzae lipase; 
ROL). These lipases were chosen because they are similar in size and structure but have widely different isoelectric points (see Table 2).

\subsubsection{Loading capacity}

Fig. 5 shows the loading capacity for the three particles. As can be seen, the amount of encapsulated enzyme for the three materials is very similar for both MML and ROL. Thus, it seems that the particle size is not an important parameter for the loading capacity. This is counter to what one would anticipate considering that smaller particles mean a larger surface area, i.e., more pores exposed to the surrounding water phase, where the enzyme is present. It

265 has previously been reported that a smaller particle size results in higher loading of enzymes $[24,25]$. However, in those studies the difference in size and character of the porous materials was very large: 1-2 $\mu \mathrm{m}$ long rods were compared with fibres extending tens of micrometers. In this work, all materials consisted of discrete, non-aggregated particles with the same average pore size, BET surface area and pore volume, which should make a comparison more relevant.

We have previously shown, for MML, that the pore size is critical for the loading capacity $[9,26]$. A pore size of $9 \mathrm{~nm}$ was found to give both high loading and good enzymatic activity while smaller pores gave both lower loading and much decreased activity. The activity of lipase encapsulated in $9 \mathrm{~nm}$ pores was, in fact, considerably higher than of lipase free in solution.

Fig. 5 shows that 10-20\% more MML is incorporated into the pores compared to ROL for all three materials. The two enzymes have the same molecular weight but differ in net charge at the $\mathrm{pH}$ used for the immobilization ( $\mathrm{pH}$ 6). As shown in Table 2, MML has a pI of 3.8 and is thus negatively charged at $\mathrm{pH} 6$ while ROL with a $\mathrm{pI}$ of 7.6 carries a net positive charge at this $\mathrm{pH}$. A probable explanation to the difference in loading is that whereas the negatively charged MML diffuses into the pores without adsorbing to the likewise negatively 
charged walls, the positively charged ROL adsorbs readily to the pore walls and thus never reaches as far into the channels.

\subsubsection{Catalytic activity}

Hydrolysis of 4-nitrophenyl acetate (pNPA) into 4-nitrophenol (pNP) was used as model reaction to test the activity of the encapsulated lipase. The catalytic activity varied significantly among the materials despite the fact that the enzyme loading was approximately the same. As shown in Fig. 6a and 6b, MPS-300 gave more than twice the yield compared to the two other materials for MML and was also considerably better for ROL. For both enzymes MPS-40 was slightly better than MPS-1000. Experiments were carried out immediately after immobilization, as well as after $24 \mathrm{~h}$ and $72 \mathrm{~h}$. Fig. $6 \mathrm{a}$ and $6 \mathrm{~b}$ show that the entrapped enzymes were quite stable. The slight decrease in yield seen for most of the samples during the first $24 \mathrm{~h}$ is probably due to enzyme leakage. However, it is interesting to see that there is not a marked difference between the two enzymes in this respect despite the

295 fact that, as discussed above, the electrostatic interactions with the pore walls should be repulsive for MML and attractive for ROL. The slight increase that is seen for MPS-300 (between $24 \mathrm{~h}$ and $72 \mathrm{~h}$ with MML and between $0 \mathrm{~h}$ and $24 \mathrm{~h}$ with ROL) may tentatively be explained by a rearrangement of the entrapped enzyme into a more favourable position or conformation.

Fig. 6c shows the specific activity of the immobilized lipases. As can be seen, for both lipases the activity was highest when encapsulated into MPS-300. A probable explanation to why the lipases have higher activity in MPS-300 compared to the larger particles, MPS-1000, is that the $300 \mathrm{~nm}$ particles have shorter pores and therefore a larger relative amount of enzyme accessible to the substrate. The lipase is believed to exert its catalytic action at the pore openings and enzymes far down the longer pores may not be utilized. 
Along this way of reasoning the smallest particles, MPS-40 would be the best hosts for the lipases, i.e., provide the highest activity of enzyme-loaded particles. This was not the case, however. We believe that the relatively poor performance of MPS-40 in this respect is due to the fact that the pores, according to TEM and nitrogen physisorption, are slit-shaped and also have a much broader pore size distribution than the two other materials. We have seen before that the size of the pores is critical and even if the average pore size of MPS-40 is the same as for MPS-300 and MPS-1000, only a small fraction of the pores in MPS-40 are actually around the optimum size of $9 \mathrm{~nm}$, see Fig. $3 \mathrm{~b}$.

\subsection{Immobilization of MML and ROL in MPS-300 at varying $\mathrm{pH}$}

Electrostatic interactions between the silica surface and enzymes are known to affect the immobilization [10,27]. To investigate whether the immobilization of MML and ROL could be further improved the entrapment was carried out at varying $\mathrm{pH}$ values. In this set of experiments MPS-300 was chosen as host for the lipases because these particles had proven to give both the highest yield and the most active lipase in the model reaction discussed in the previous section.

\subsubsection{Loading capacity}

The amount of loaded MML and ROL in MPS-300 at pH 5, 6, 7 and 8 is shown in Fig. 7a. It can be seen that the loading of MML increased with decreasing $\mathrm{pH}$. The isoelectric point (pI) of MML is 3.8 and the point of zero charge (pzc) of silica is around 2. Since the $\mathrm{pH}$ of all the buffers used was above both the pzc for silica and the pI for MML, both the pore walls and the lipase molecules carried a negative net charge. The lower the $\mathrm{pH}$ within the series the less pronounced is the negative surface charge of both silica and MML, which means lower electrostatic repulsion between MML and silica, as well as between MML molecules. The trend is therefore according to expectations. 
The loading of ROL did not vary much with the $\mathrm{pH}$. The $\mathrm{pI}$ of ROL is 7.6, which means that the enzyme has a positive net charge at $\mathrm{pH} 5,6$ and 7 and is slightly negatively charged at $\mathrm{pH}$ 8. The lower the $\mathrm{pH}$ within the interval 5-7, the more pronounced is the positive net charge of ROL but the less pronounced is the negative surface charge of silica. It is therefore not obvious how the Columbic attraction between the lipase and the pore walls will vary with $\mathrm{pH}$. The repulsion between ROL molecules will, however, increase with a reduction in $\mathrm{pH}$. At the highest $\mathrm{pH}, \mathrm{pH} 8$, one may at first anticipate a repulsive interaction between the slightly negatively charged ROL and the strongly negatively charged silica surface. However, this may not be the dominating interaction. The enzyme may adopt a conformation such that it exposes positively charged groups toward the silica surface, leading instead to an attractive enzyme-silica interaction, similar to the situation at the lower $\mathrm{pH}$ values. It is known that enzymes adsorb readily at negatively charged surfaces also well above their pI $[28,29]$.

Fig. $7 \mathrm{~b}$ and 7c show the leakage of MML and ROL, respectively, after $24 \mathrm{~h}$ at varying $\mathrm{pH}$. One may note that for MML, where both the enzyme and the pore walls are negatively charged, there is considerable leakage, particularly at the lower $\mathrm{pH}$ values. For ROL, on the

345 other hand, where one can assume attractive interactions - caused by an increase in entropy as a result of release of counterions [30] - there is virtually no leakage during the first $24 \mathrm{~h}$. Extending the time beyond $24 \mathrm{~h}$ gave no further leakage of any of the lipases.

\subsubsection{Catalytic activity}

The catalytic activity of MML and ROL immobilized in MPS-300 particles at varying pH was studied during $360 \mathrm{~h}$ and was compared with the two lipases free in solution. The lipases are referred to as MML-Y or ROL-Y, where $\mathrm{Y}$ is the $\mathrm{pH}$ of the buffer during the immobilization. The enzymatic reactions were all carried out in $50 \mathrm{mM}$ phosphate buffer of pH 7. Fig. 8a shows that the yields obtained with MML entrapped in the mesoporous silica were quite similar despite the large difference in loading amount (Fig. 7). For MML-5 the 
355 product yield was significantly lower after $96 \mathrm{~h}$ compared to the initial yield. MML-6 also showed a slight initial decrease in yield. A probable explanation to this initial drop in product yield is the leakage during the first $24 \mathrm{~h}$, which, as shown in Fig. 7 and discussed above, was more pronounced the lower the $\mathrm{pH}$ during the immobilization. For MML-7 there was no decrease in yield and MML-8 even exhibited a slight increase in product yield with time. This 360 yield increase may be due to a rearrangement of the lipase into a more favorable position or conformation, as discussed in Section 3.2.2. Throughout the $360 \mathrm{~h}$ of measurements the immobilized MML remained stable whereas MML free in solution lost more than $65 \%$ of its initial activity.

ROL entrapped in the mesoporous particles exhibited a different behavior with respect to 365 the $\mathrm{pH}$ during the immobilization. As can be seen in Fig. 8b, entrapment at $\mathrm{pH} 7$ and 8 gave considerably higher yield than when the entrapment was made at $\mathrm{pH} 5$ and 6. (One should recall that the activity tests were all conducted at $\mathrm{pH} 7$; it is only the $\mathrm{pH}$ of the immobilization that differs.) Since the amount of ROL loaded into the particles is approximately the same regardless of the $\mathrm{pH}$ and the leakage is negligible (see Fig. 7), this indicates that the enzyme 370 loses activity during immobilization at the lower $\mathrm{pH}$ values. Fig. $8 \mathrm{~b}$ also shows that ROL free in solution gives approximately the same yield as the best immobilized enzymes and remains stable with time. The pronounced difference between MML, for which entrapment into the pores of mesoporous silica is highly advantageous, and ROL, for which the native enzyme is as effective as the immobilized, is interesting and an attempt to explain the reason for this 375 difference is made below.

Looking at the specific activity (Fig. 8c) instead of product yield it becomes very clear that both MML and ROL were most active when immobilized at $\mathrm{pH} 8$ and that the activity decreased with decreasing $\mathrm{pH}$ during the immobilization. (Again, it should be emphasized that all activity tests were performed in a phosphate buffer of $\mathrm{pH}$ 7.) This means that for 
MML, the more than four times higher loading that was achieved at $\mathrm{pH} 5$ compared to $\mathrm{pH} 8$ was outweighed by a corresponding decrease in specific activity. The results point at the importance of immobilizing MML in its most active state, i.e., at $\mathrm{pH}$ 8. Thus, it appears that the conformation attained during the entrapment at a certain $\mathrm{pH}$ is to some extent conserved after the immobilization.

Fig. 8c also shows that the specific activity of MML-8 was more than four times as high as of MML free in solution. Many lipases, including MML and ROL, are characterized by a lid that covers the active site in solution and which exposes it when in contact with a hydrophobic surface. As discussed in our previous communication, the environment inside the pores may be favorable for activating the lipase [9]. Many of the silanol groups situated on the silica surface are lost during the calcination step, which leads to the pore walls being relatively hydrophobic. Therefore an interfacial activation of lipase in contact with the pore walls seems reasonable. The interfacial activation of ROL was much less pronounced, however.

Surface tension measurements of the two lipases $(2 \mathrm{mg} / \mathrm{ml})$ in phosphate buffer $\mathrm{pH} 7$ 395 gave a surface tension of MML of $47 \mathrm{mN} / \mathrm{m}$ whereas the surface tension of ROL was 60 $\mathrm{mN} / \mathrm{m}$. The same surface tension values were obtained both with $100 \mathrm{mM}$ buffer, which corresponds to the electrolyte concentration during the immobilization, and with $50 \mathrm{mM}$ buffer, which is the electrolyte concentration used in the activity tests. Thus, MML is considerably more surface active than ROL. This indicates that MML will interact more strongly with hydrophobic patches on the silica pore walls, which could explain why its activity is more enhanced when situated inside the pores compared to ROL.

The surface charge of the lipase molecules can also be a contributing factor to the difference in interfacial activation. Depending on how the surface charges are distributed over the lipase molecules the enzymes can be bound to the silica walls in different manners, and 
405 the lid might either be facing the silica surface or the bulk. Comparing the amino acid sequences of MML and ROL shows that the amount of charged amino acid side chains differs, hence the difference in pI. MML has 28 polar acidic side chains and 21 polar basic side chains whereas ROL has 22 polar acidic side chains and 31 polar basic side chains. However, the tertiary structure of ROL is not known and therefore it is not possible to

410 compare the surface charge distribution in space between the two enzymes. Thus, it is difficult to relate the known difference in amount of positive and negative charges of the two enzymes to possible differences in interaction of the lids with the pore walls.

\section{Conclusions}

Three types of discrete mesoporous silica particles with varying particle morphology and 415 particle size $(1000 \mathrm{~nm}, 300 \mathrm{~nm}$ and $40 \mathrm{~nm})$ were synthesized. When immobilizing lipase from Mucor miehei (MML) and Rhizopus oryzae (ROL) into the pores of the three particle types it was found that the loading did not differ significantly. However, the specific activity was clearly affected by the particle size and morphology. Both lipases were most active when immobilized into the $300 \mathrm{~nm}$ particles. Immobilization into these particles was further studied at different $\mathrm{pH}$ values within the interval 5 to 8 . The loading of MML was more than four times higher at $\mathrm{pH} 5$ compared to $\mathrm{pH}$ 8. The specific activity, determined at a $\mathrm{pH}$ of 7 , followed an opposite trend with the particles loaded at $\mathrm{pH} 8$ being the most active. The loading of ROL did not vary much with the $\mathrm{pH}$, while the specific activity of ROL was also highest when immobilized at $\mathrm{pH}$ 8. The results point at the importance of immobilizing both MML and ROL in their most active states, i.e., at $\mathrm{pH}$ 8. Immobilized MML was much more active compared to MML free in solution whereas for ROL there was not much difference in activity between free enzyme and enzyme immobilized at $\mathrm{pH}$. The fact that MML but not ROL became much more active when entrapped in the pores than free in solution may be due 
to MML being much more surface active than ROL. MML is therefore likely to interact more

430 strongly with the relatively hydrophobic pore walls. It is well known that most lipases become activated through interaction between the lid covering the active site and a surface. The difference in surface charge of the two lipases can also be a contributing factor to the difference in interfacial activation.

\section{Acknowledgements}

435 Emma Johansson and Magnus Odén thank Nanolith Sverige AB for economic support. The staff of MAX-lab, Sweden is acknowledged for providing access at the I911 SAXS scattering beamline.

This project is part of the Linnaeus Centre for Bio-inspired Supramolecular Function and Design - SUPRA, which is funded by the Swedish Research Council. 


\section{References}

[1] Díaz, J. F., Balkus, K. J. J., Mol. Cat. B: Ensym. 2 (1996) 115.

[2] Yiu, H. H. P., Wright, P. A., Botting, N. P., Micropor. Mesopor. Mater. 44 (2001) 763.

[3] Takimoto, A., Shiomi, T., Ino, K., Tsunoda, T., Kawai, A., Mizukami, F., Sakaguchi, K., Micropor.

445

[4] Handa, P., Stjerndahl, M., Holmberg, K., Micropor. Mesopor. Mater. 100 (2007) 146.

[5] Handa, P., Holmberg, K., Sauthier, M., Castanet, Y., Mortreux, A., Micropor. Mesopor. Mater. 116 (2008) 424.

[6] Reis, P., Witula, T., Holmberg, K., Micropor. Mesopor. Mater. 110 (2008) 355.

450 [7] Takahashi, H., Li, B., Sasaki, T., Miyazaki, C., Kajino, T., Inagaki, S., Micropor. Mesopor. Mater. 44 (2001) 755.

[8] Wan, Y., Zhao, D. Y., Chem. Rev. 107 (2007) 2821.

[9] Gustafsson, H., Thörn, C., Holmberg, K., Colloids Surf. B 87 (2011) 464.

[10] Deere, J., Magner, E., Wall, J. G., Hodnett, B. K., J. Phys. Chem. B 106 (2002) 7340.

455 [11] Weber, E., Sirim, D., Schreiber, T., Thomas, B., Pleiss, J., Hunger, M., Glaser, R., Urlacher, V. B., J Mol Catal B-Enzym. 64 (2010) 29.

[12] Gao, S., Wang, Y., Diao, X., Luo, G., Dai, Y., Bioresour. Technol. 101 (2010) 3830.

[13] Zhao, D. Y., Huo, Q. S., Feng, J. L., Chmelka, B. F., Stucky, G. D., J. Am. Chem. Soc. 120 (1998) 6024.

460 [14] Zhao, D. Y., Feng, J. L., Huo, Q. S., Melosh, N., Fredrickson, G. H., Chmelka, B. F., Stucky, G. D., Science 279 (1998) 548.

[15] Johansson, E. M., Ballem, M. A., Córdoba, J. M., Odén, M., Langmuir 27 (2011) 4994.

[16] Nandiyanto, A. B. D., Kim, S.-G., Iskandar, F., Okuyama, K., Micropor. Mesopor. Mater. 120 (2009) 447.

465 [17] Barrett, E. P., Joyner, L. G., Halenda, P. P., J. Am. Chem. Soc. 73 (1951) 373.

[18] Brunauer, S., Emmett, P. H., Teller, E. J., Am. Chem. Soc. 60 (1938) 309.

[19] Yu, C., Tian, B., Fan, J., Stucky, G. D., Zhao, D., J. Am. Chem. Soc. 124 (2002) 4556.

[20] Jin, Z., Wang, X., Cui, X., Colloids Surf. A 316 (2008) 27.

[21] Sayari, A., Han, B.-H., Yang, Y., J. Am. Chem. Soc. 126 (2004) 14348.

470 [22] Johansson, E. M., Cordoba, J. M., Oden, M., Micropor. Mesopor. Mater. 133 (2010) 66.

[23] Sing, K. S. W., Everett, D. H., Haul, R. A. W., Moscou, L., Pierotti, R. A., Rouquerol, J., Siemieniewska, T., Pure Appl. Chem. 57 (1985) 603.

[24] Fan, J., Lei, J., Wang, L., Yu, C., Tu, B., Zhao, D., Chem. Commun. (2003) 2140.

[25] Lei, J., Fan, J., Yu, C., Zhang, L., Jiang, S., Tu, B., Zhao, D., Micropor. Mesopor. Mater. 73 (2004) 121.

[26] Thörn, C., Gustafsson, H., Olsson, L., J. Mol. Catal. B: Ensym. 72 (2011) 57.

[27] Serra, E., Mayoral, A., Sakamoto, Y., Blanco, R. M., Diaz, I., Micropor. Mesopor. Mater. 114 (2008) 201.

[28] Matuszewska, B., Norde, W., Lyklema, J., J. Colloid Interface Sci. 84 (1981) 403.

480 [29] Lyklema, J., Colloids Surf. 10 (1984) 33.

[30] Holmberg, K., Jönsson, B., Kronberg, B., Lindman, B., (2003). Surfactants and Polymers in Aqueous Solution. Wiley, Chichester.

[31] Wu, X., Jääskeläinen, S., Linko, W.-Y., Appl. Biochem. Biotechnol. 59 (1996) 145.

[32] Hiol, A., Jonzo, M. D., Rugani, N., Druet, D., Sarda, L., Comeau, L. C., Ensyme Microb. Technol. 26 (2000) 421. 


\section{Tables}

490 Table 1. Material properties of mesoporous silica particles analyzed by nitrogen adsorption.

\begin{tabular}{llll} 
Material & $\begin{array}{l}\text { BJH pore } \\
\text { width }(\mathrm{nm})\end{array}$ & $\begin{array}{l}\text { BET surface area } \\
\left(\mathrm{m}^{2} / \mathrm{g}\right)\end{array}$ & $\begin{array}{l}\text { Total pore volume } \\
\left(\mathrm{cm}^{3} / \mathrm{g}\right)\end{array}$ \\
\hline MPS-1000 & 9.3 & 502 & 1.18 \\
MPS-300 & 9.4 & 606 & 1.03 \\
MPS-40 & 9.1 & 463 & 0.91 \\
\hline
\end{tabular}

Table 2. Isoelectric point $(\mathrm{pI})$ and molecular weight $\left(\mathrm{M}_{\mathrm{W}}\right)$ of Mucor miehei lipase (MML) and Rhizopus oryzae lipase (ROL).

\begin{tabular}{lll} 
Enzyme & $\mathrm{pI}$ & $\mathrm{M}_{\mathrm{W}}(\mathrm{kDa})$ \\
\hline $\mathrm{MML}^{\mathrm{a}}$ & 3.8 & 32 \\
ROL $^{\mathrm{b}}$ & 7.6 & 32 \\
\hline
\end{tabular}

${ }^{\mathrm{a}}$ Reference [31].

$495{ }^{\mathrm{b}}$ Reference [32]. 


\section{Figure captions}

Fig. 1. SEM micrographs of the mesoporous silica particles. (a) MPS-1000, (b) MPS-300, (c) MPS-40, and (d) close-up of MPS-40.

Fig. 2. TEM micrographs of the mesoporous silica particles. (a) MPS-1000, (b) MPS-300, (c) MPS-40, and (d) close-up of MPS-40.

Fig. 3. Nitrogen sorption measurements. (a) Nitrogen adsorption-desorption isotherms and (b) the pore size distribution of the mesoporous materials.

505 Fig. 4. SAXS patterns of the mesoporous materials. (a) MPS-300 and (b) MPS-40.

Fig. 5. Immobilization of MML and ROL into MPS-1000, MPS-300 and MPS-40 in phosphate buffer of pH 6.

Fig. 6. (a) Yield of 4-nitrophenol using MML entrapped in MPS-1000, MPS-300 and MPS-40. (b) Yield of 4nitrophenol using ROL entrapped in MPS-1000, MPS-300 and MPS-40. (c) Comparison of the specific activity for MML and ROL (amount of product/mass of enzyme) entrapped in MPS-1000, MPS-300 and MPS-40.

510 Fig. 7. (a) Immobilization of MML and ROL into MPS-300 in phosphate buffers of pH 5, 6, 7 and 8. Amount of (b) MML and (c) ROL in MPS-300 initially and after $24 \mathrm{~h}$ exposure to water.

Fig. 8. (a) Yield of 4-nitrophenol using MML entrapped in MPS-300 at $\mathrm{pH} 5,6,7$ and 8. (b) Yield of 4-

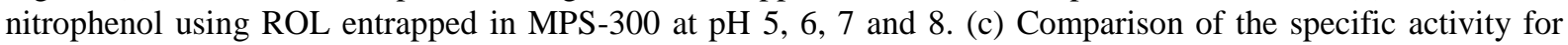
MML and ROL (amount of product/mass of enzyme) at $\mathrm{pH} 5,6,7$ and 8. 


\section{Figures}

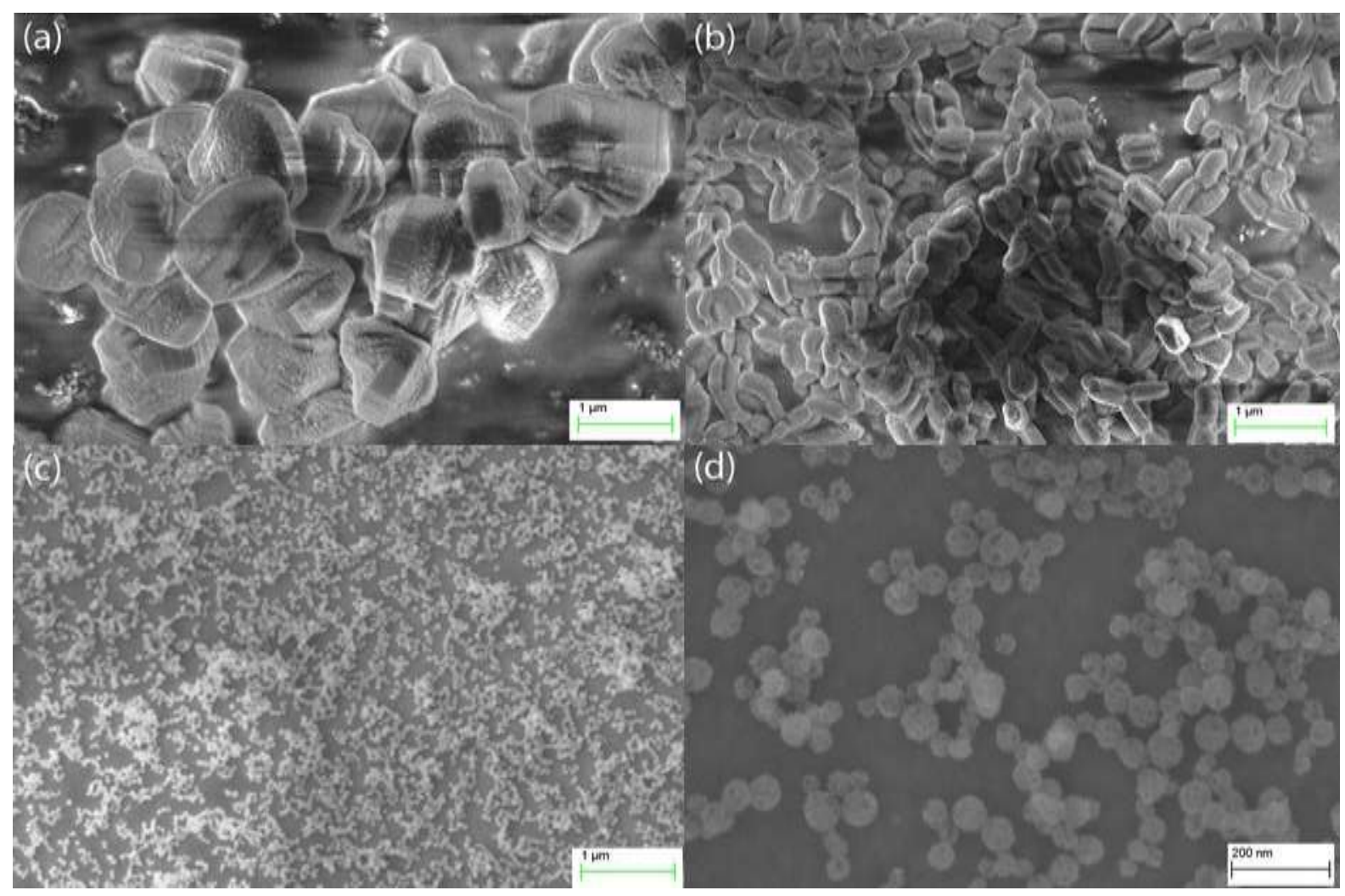

Fig. 1.

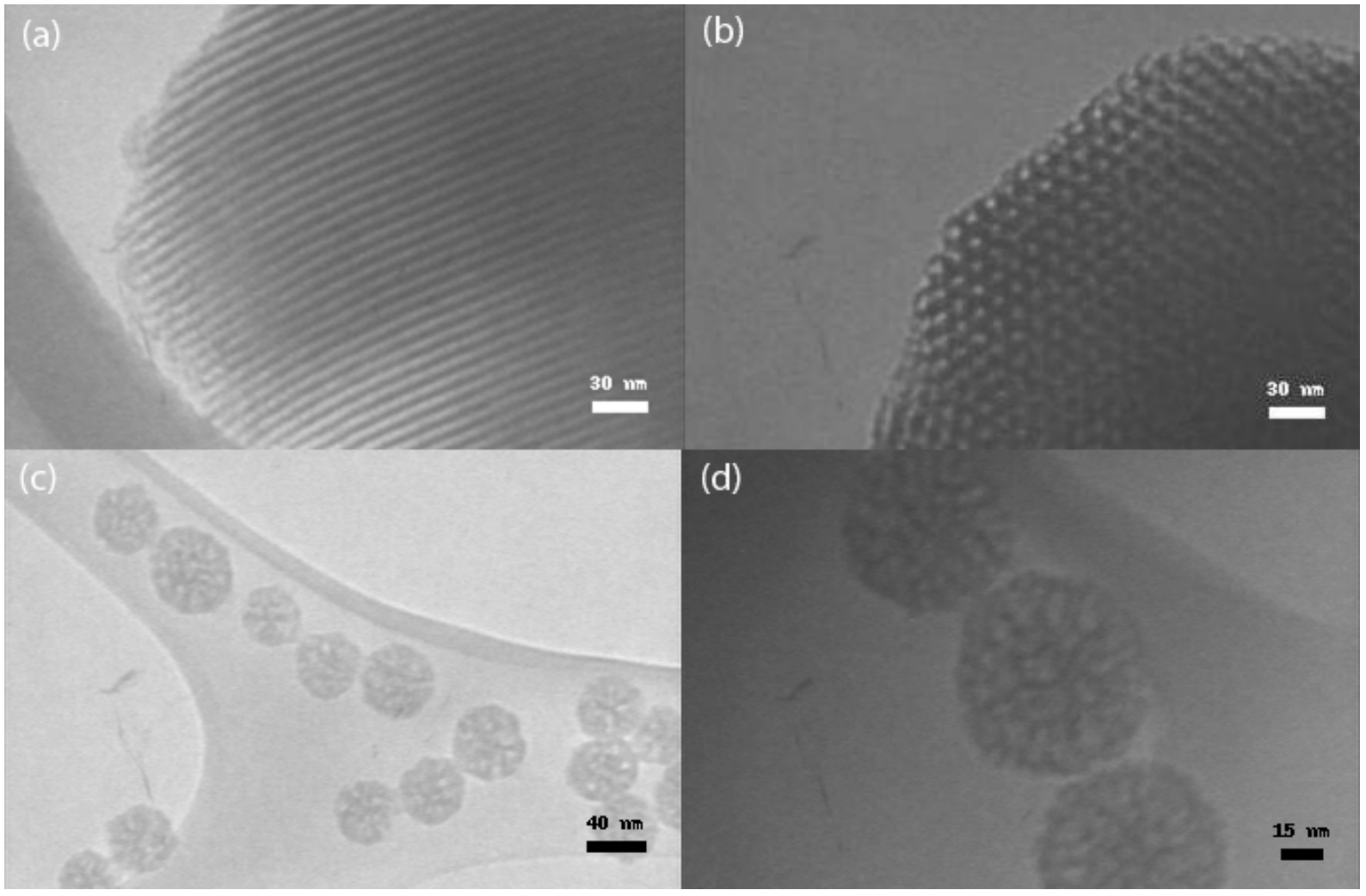


Fig.2.
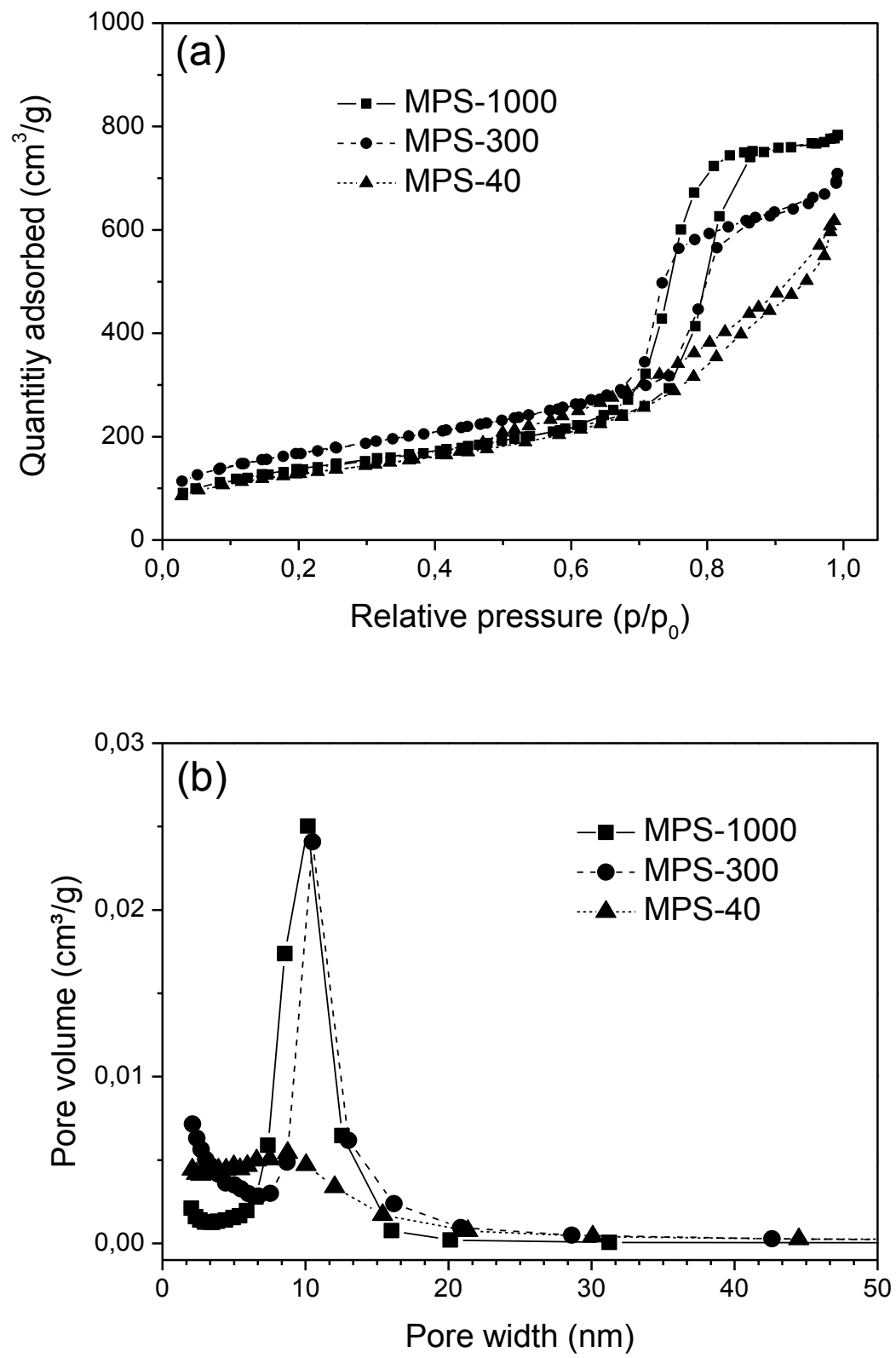

Fig.3. 


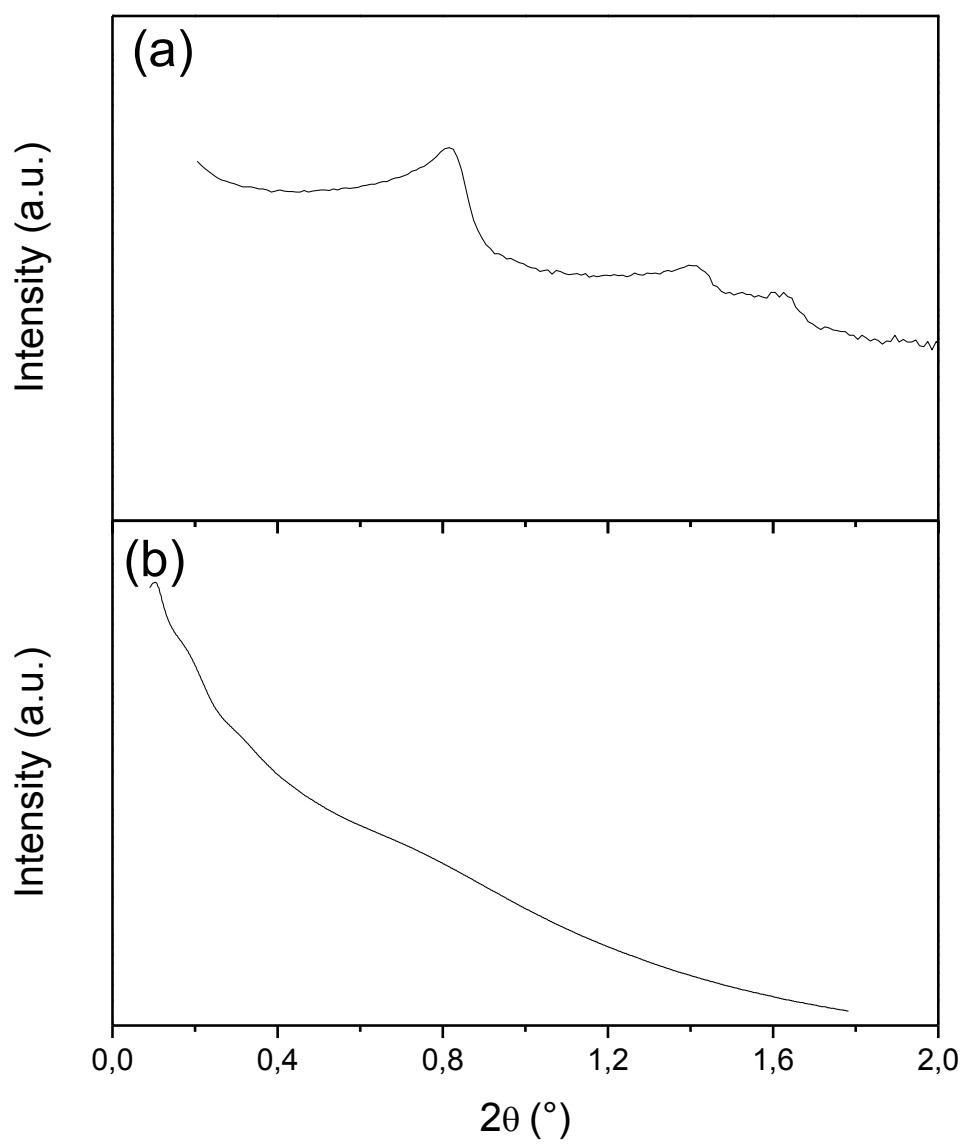

525

Fig. 4.

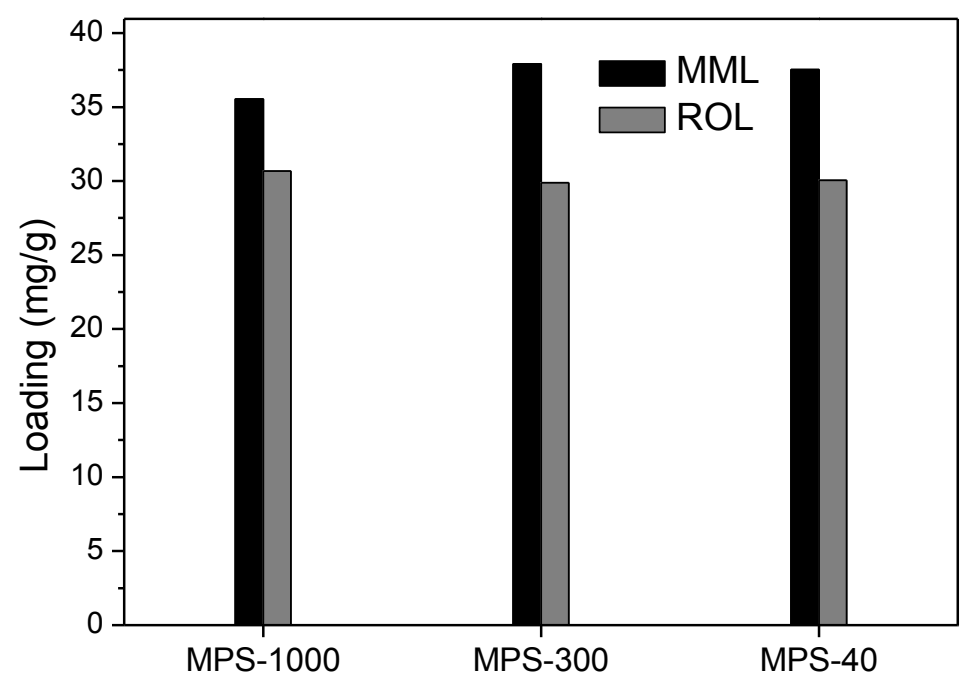

Fig. 5. 

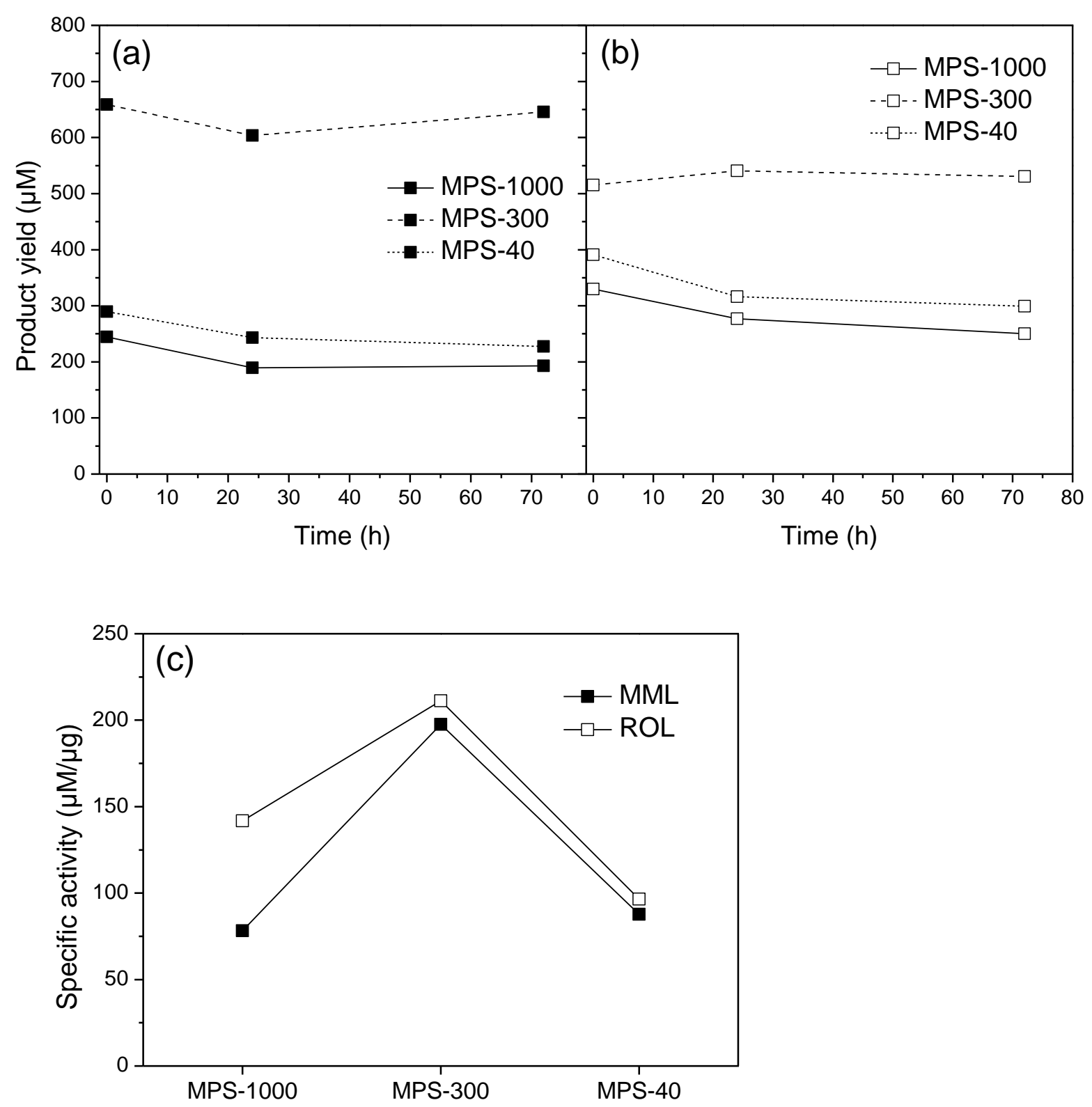

Fig. 6. 


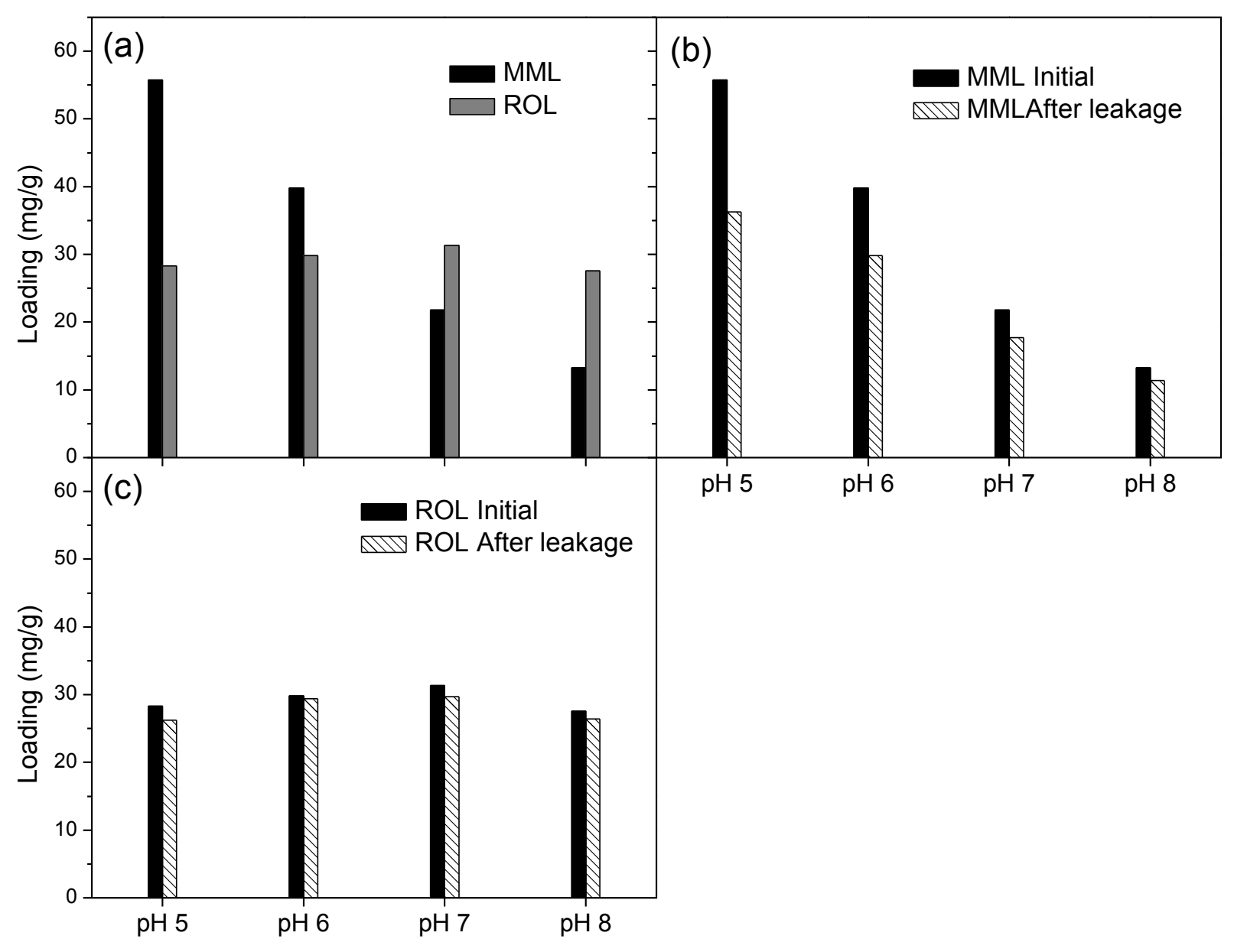

Fig. 7. 

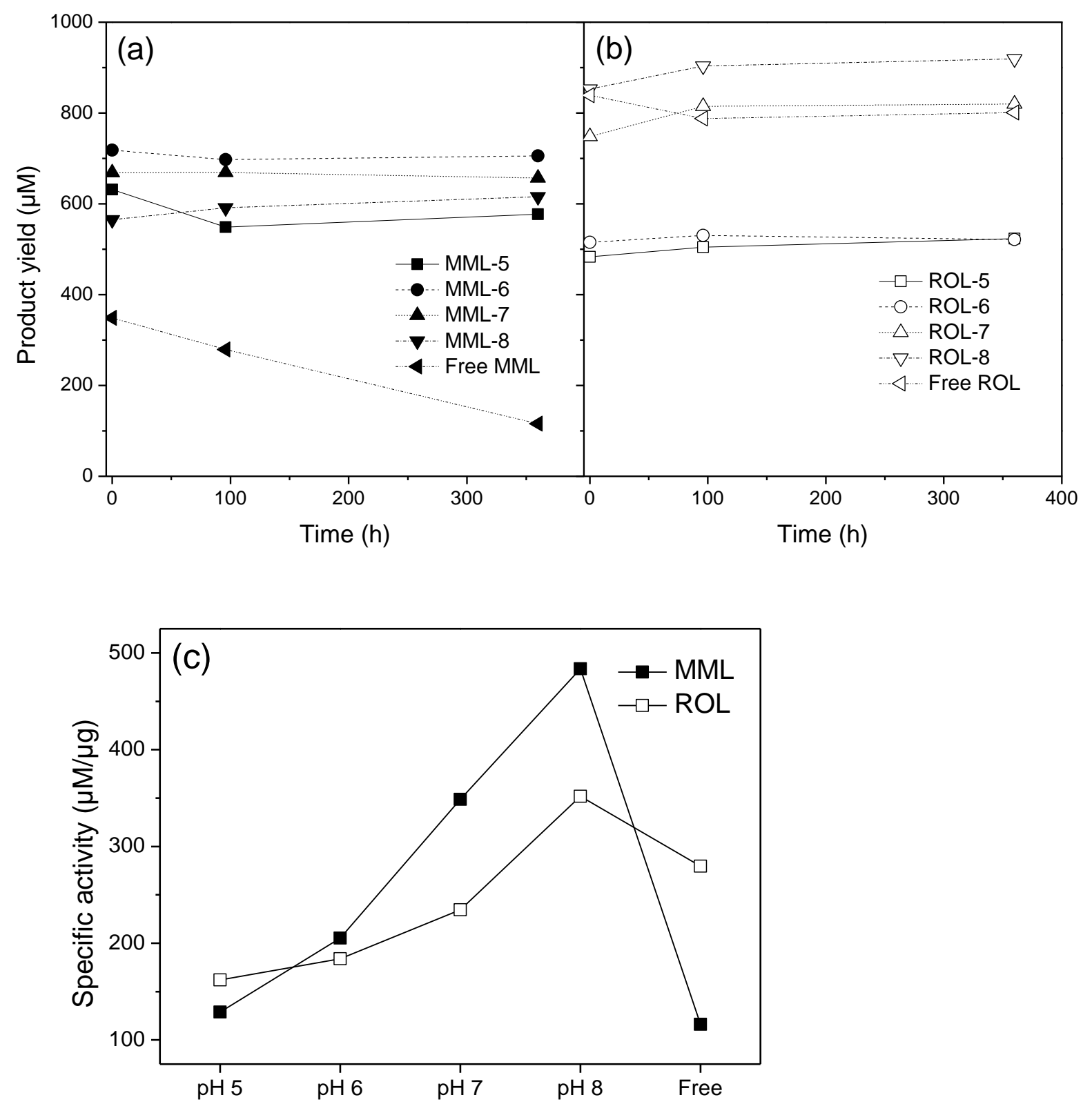

Fig. 8 . 